\title{
Cite them right - is it an essential referencing guide?
}

\section{Elisabeth Wilding}

University of Reading

\section{Overview}

This 2010 publication is the eighth edition of Cite them right, now published by Palgrave Macmillan, the well-known producer of study skills handbooks for secondary and higher education. The book describes itself as a 'guide to referencing and avoiding plagiarism' and is designed for a wide range of users; from secondary to post-graduate levels and for students, researchers, and authors. This new edition contains many updates to reflect the ever expanding and changing world of electronic publishing, which means that most students now locate information via the internet.

\section{Layout and structure}

Visually, Cite them right is clean and unfussy, with an attractive simplicity to the style. The boxed examples stand out from the text and the use of simple colour-coding makes them easy to read. In terms of overall layout, the book is easy to use and information can be located without difficulty. The organisation is clear, the sections are well-marked and there is a logical progression through from beginning to end, although it would rarely be read this way.

\section{Content}

Of the nine sections of Cite them right, six of them focus on providing specific referencing examples - the main strength of this book - while the remaining three offer more general information. I will briefly review the main sections below (Sections $A$ to $C$ ) but with a stronger focus on the central reference section of the book (Section $\mathrm{D}$ ). 
Section A provides an introduction to referencing and how to avoid plagiarism. This brief section does present some information in a clear and very succinct manner. However, three pages cannot in any way do justice to this topic and it feels so cursory that it verges on being little more than lip-service. Perhaps it could provide a review for a motivated and willing reader with prior knowledge. But for students/readers who either do not already know the essential principles of referencing, do not fully understand what they mean, or do not have the skills to implement them, this section would not help develop learning or understanding in any meaningful way.

Sections $B$ and $C$ are designed to cover the basics of author-date style referencing, which should be understood before going on to the examples in the following pages. Section $B$ provides basic information on the conventions for how to set out citations and quotations in-text. Brief sub-sections on paraphrasing and summarising are included here, but without original texts to compare with the examples given, these are not particularly helpful. Section $C$ explains how to set out references at the end of a text. Most relevant seems to be the sample text and reference list given at the end of the section, so students working through the book can see a model of good practice. There is a also a useful checklist of the information that is needed in order to compile a correct reference list - making it clear, for example, how different information is required for a book as opposed to an internet site.

The authors have chosen to use the Harvard system for their examples, something that is clearly stated in the foreword, although I wonder if some hurried and over-eager students might miss this detail and spend too much time in sections $B$ and $C$ unsure of which system is being used as this detail is not repeated again in these sections. No mention is made of why the Harvard system has been chosen here. It is one of the more widely used systems, but it might have been interesting to hear why this was preferred over other author-date systems, such as APA. For readers, it is a definite advantage to have a book such as this which can function as a definitive model for Harvard style referencing - a system that lacks a single authority to define it - and which therefore lacks common agreement on its exact format. There is a place for a definitive reference guide such as this towards which educators can direct their students (or can even use themselves).

Section D - how to cite and reference sources using Harvard style - is really the core of Cite them right. Fifty pages (out of the book's 98) are given over here to extensive guidance and examples on how to reference in the Harvard style. These examples are, for 
me, the highlight of this book. The whole section is generally easy to use and clearly laid out. Twenty-five different categories of sources are covered, starting with printed books and then progressing all the way through less commonly used sources to finish with manuscripts. For each source an example illustrates how to provide an in-text citation and a reference list. This section is comprehensive and will provide answers to most questions about how to reference correctly. As stated above, this new edition features a wide array of internet sources such as TV programmes viewed on the internet; social networking websites; messages from course discussion boards; or photos in online collections (to list just a few examples). Access to the information is facilitated by the index at the back, so a user can dip in for specific help and find it quickly.

The final five sections in the book cover some other commonly-used referencing styles: APA, MLA, MHRA, OSCOLA, and Vancouver. These other styles are treated in the main by reference to Harvard style and how they may differ from this. For this reason, the book would work best for those who use the Harvard system because it is much more comprehensive in this area. Nevertheless, these final guides do once again provide clear examples as a model throughout and are a positive addition to the book.

The book ends with an essential index (mentioned above), which, along with the section specifically on Harvard referencing, will likely be the most-used part of Cite them right.

\section{Verdict}

How does it rate overall? As a referencing guide, this book is first rate. It might seem a little daunting at first, but if used the way it is designed to be handled it is actually very user-friendly. This is not a book to read from beginning to end, but rather one to be searched (via the contents or the index) for relevant information. The secondary task of how to avoid plagiarism is treated in a rather cursory manner and remains little more than a summary of best practice, so this part of the book seems to have less positive value. I would definitely recommend this book for libraries and self-access centres as an essential guide for students on how to reference correctly.

Given the speed at which our ways of finding information have been changing so quickly there is a danger that a print edition such as Cite them right will become quickly out of 
date. The real competition for such books may well come from internet referencing guides provided online by organisations and institutions which can be updated more frequently than a book ever can. Nevertheless, the comprehensive scope of this latest edition is more than enough for now to make it a valuable addition to any reference collection.

\section{References}

Pears, R. and Shields, G. (2010) Cite them right: the essential referencing guide. $8^{\text {th }}$ edn. Basingstoke: Palgrave MacMillan.

\section{Author details}

Dr Elisabeth Wilding is Senior Academic Tutor for the International Foundation Programme at the University of Reading, where she teaches EAP and Academic Skills to international students. 